\title{
Estimated Pollution Reduction from Wind Farms in Oklahoma and Associated Economic and Human Health Benefits
}

\author{
J. Scott Greene ${ }^{1}$ and Mark Morrissey ${ }^{2}$ \\ ${ }^{1}$ Department of Geography and Environmental Sustainability, University of Oklahoma, Norman, OK 73019, USA \\ ${ }^{2}$ School of Meteorology, University of Oklahoma, Norman, OK 73019, USA
}

Correspondence should be addressed to J. Scott Greene, jgreene@ou.edu

Received 28 August 2012; Accepted 21 October 2012

Academic Editor: Surya Santoso

Copyright ( 2013 J. S. Greene and M. Morrissey. This is an open access article distributed under the Creative Commons Attribution License, which permits unrestricted use, distribution, and reproduction in any medium, provided the original work is properly cited.

\begin{abstract}
Over the past few decades, there has been a recognition of the growing need for different forms of energy outside of fossil fuels. Since the latter half of the twentieth century individuals, corporations, and governments have become increasingly aware of the effects of the emissions of carbon and other harmful pollutants on the environment. With this greater concern has come increasing activity to combat these harmful emissions by using alternative fuel sources to power homes, businesses, and cities. As can be seen from recent trends in their installed capacity, it is clear that renewable energy resources will continue to be more commonly used in the future. As renewable energy increases, a decrease in a range of harmful pollutants from the energy sector will also occur. This paper provides a case study to estimate the potential environmental and health benefits of an increased shift from fossil fuels to renewable fuels for electrical production in Oklahoma. Results illustrate and quantify the specific reduction that wind energy can and will have on air quality, as well as provide a quantification of the associated potential health benefits.
\end{abstract}

\section{Introduction}

Since the latter half of the twentieth century individuals, corporations, and governments have become increasingly aware of the effects of pollution emissions on the environment. International organizations such as the G8 group of leading economic countries have also recognized the importance of renewable energy for sustainable development, as well as for energy security, diversification of energy supply, and environmental preservation. With this greater concern has come increasing activity to combat these harmful emissions by using alternative fuel sources to power homes, businesses, and cities. For example, 2011 saw the United States pass the $46 \mathrm{GW}$ mark for installed electrical generation capacity by wind [1]. The overall world total installed capacity is over 240 GW. This represents a tremendous amount of growth over the last few decades as there was almost no installed capacity in the year 1980 .

With this rapid expansion of a new technology comes many questions. For example, environmental impacts of a shift in electrical production to wind needs to be examined.
Although there are a range of potential environmental impacts of renewable energy (e.g., impact on wildlife, etc.; see US Department of Energy [DOE] [2], National Science Foundation (NSF) [3]) there have been few studies of the impact on emission of harmful pollutants. This list would include Sulphur Dioxide $\left(\mathrm{SO}_{2}\right)$, Nitrous Oxides $\left(\mathrm{NO}_{X}\right)$, and Carbon Dioxide $\left(\mathrm{CO}_{2}\right)$. The first two pollutants have long been known to have harmful impact on human health, as there have been a vast number of studies examining the relationships ([4-6], etc.). Regarding Carbon Dioxide, there have also been studies (e.g., [7], and many others) that have shown the negative health implication of increased global temperatures associated with increased Carbon Dioxide. Only recently, however, has Carbon Dioxide officially been declared a harmful pollutant by the US Environmental Protection Agency (EPA). As pointed out by Lu et al. [8], "Wind power can make an important contribution to the goal of reducing emissions of $\mathrm{CO}_{2}$ ". Thus, with the world becoming ever more aware of the effects of carbon and other pollution emissions on our planet, the matter of whether or not wind will be able to supply the country with clean electricity is 
at the forefront of many minds. Much of the research in the area of wind power generation tends to focus on issues such as the examination of the wind resource, $[9,10]$ cost of production, the maximum amount of electricity that wind power may be able to provide, and the potential environmental impact to wildlife, and so forth [2]. However, less has been written about the environmental savings associated with the pollution reduction associated with the switch from "grey" fossil energy to "green" energy such as wind energy (although there have been studies by Denny and O'Malley [11] and others). In the present paper, the role that wind power generation plays in reducing the emissions of $\mathrm{SO}_{2}, \mathrm{NO}_{X}$, and $\mathrm{CO}_{2}$ will be investigated in a case study of Oklahoma. Using well-established methodology from the DOE, the US Energy Information Agency (EIA), and the refereed literature, emissions reductions associated with the installation of wind will be computed. After these values are estimated for the past decade in Oklahoma, an estimation of the potential health and cost savings associated with this pollution reduction is undertaken.

\section{Methods}

This work follows along other studies which have attempted to quantify the known impact of the reduction in pollution associated with wind energy. The DOE [2] issued a roadmap of how the US might obtain $20 \%$ of electricity generation from wind energy by 2030. Using the WinDS model [12] it was determined that in order to reach the required $20 \%$, over $300 \mathrm{GW}$ of installed capacity wind energy would need to be installed throughout the country (see also [13]). Substituting this $20 \%$ of wind energy in place of carbon generation methods yields an annual reduction in carbon emissions of 225 Million Metric Tons [2]. This shows support for the hypothesis that wind power can promote decreased emissions when used as a significant portion of the energy generation mix. A similar study was undertaken in Belgium by the Kuleuven Energy Institute [14] with a stated purpose of examining the effect of installing wind energy on both cost, reliability, and carbon emissions. Unlike the DOE report, this study had a primary focus on investigating the effect that installing wind energy will have on emissions.

Delarue et al. [15] provided a model on how to investigate wind emissions. They investigated multiple scenarios for possible wind energy development. Each simulation used a different wind resource model and a different energy load model. For the purpose of the simulations, four load models designed to reflect realistic demand on the Belgian power grid were created. These were (1) electrical demand during a weekday in winter, (2) electrical demand during a weekend in winter, (3) electrical demand during a weekday in summer, and (4) electrical demand during a weekend in summer [15]. These load models were applied to different wind resource models ascertained by collection of wind resource data from different locations, including a sheltered area with relatively stable low wind resources, an area of high variability in the available wind resource, and an area of a relatively consistent high wind resource [15]. Delarue et al. [15] discuss the reduction of carbon emissions as a function of the installed wind generation capacity. Utilizing these simulations, they found that the amount of carbon emissions reduced was equal to approximately 10.8 metric tons per MW of installed wind energy per day. Similar studies by Gil and Joos [16], Holttinen and Tuhkanen [17], Katzenstein and Apt [18] provide models for estimating displaced emissions by wind generation. Each of these make different assumptions regarding types of turbines, installed capacity, fuel energy blend, and so forth. All of these models have a goal of investigating the approach to develop new innovative methodology. As such they all involve a level of sophistication which is beyond the scope and intent of the current project, as the efforts described here are designed to illustrate projected emissions savings rather than develop new methodology.

\section{Case Study}

For this particular study, an approach similar to the studies outlined above is used to examine the expected impacts of wind energy in Oklahoma on pollution emissions reduction. This project has been undertaken by the Oklahoma Wind Power Initiative [19]. The Oklahoma Wind Power Initiative began in July 2000 with a mission to develop wind resource models and products, to provide educational outreach to officials and citizens, and to study policies in other states and the nation that are promoting development of wind power. Partly as a result of OWPI's efforts at organizing stakeholders and educating the public, Oklahoma has seen significant development of utility-scale wind farms, resulting in over $\$ 1$ billion in economic development for the state in the last few years. For example, in 2010, these wind farms have a total direct and indirect jobs supported of almost 2,000, annual property tax payments by wind project owners of over $\$ 9$ million, and annual land lease payments of nearly $\$ 4.5$ million. In 2011, Oklahoma ranked seventh in net electricity generation from wind, which provided 7.1 percent of the State's net generation [20]. The net electricity generation from wind has reached as high as $17 \%$ for some of the state's utilities. Figure 1 [21], Figure 2 [22], and Figure 3 [23] provide an illustration of the Oklahoma wind resource. Figure 1 shows the installed capacity of wind energy across the United States. Oklahoma ranks 9th in state wind resource in the US, with an estimated potential of over 500,000 MW at 80 meter hub heights. This resource could provide over 25 times state's current electricity needs [20]. Figure 2 is a map of the wind resource in the state. The wind power class refers to an estimate of the wind resource; the higher the class, the greater the wind speed, and, thus, the greater the potential for wind energy production. Class 3 or above is typically considered economically viable. Figure 3 provides an illustrative representation as to where the Oklahoma wind farms are located.

As Delarue et al. [15] point out, "to correctly investigate the effects of wind power, it is necessary to embed wind turbines in a wider power system and to take a look at the overall picture." To place wind in the overall picture to compute the emissions reduction, the blend of electricity prewind was determined (for this study, 2001 was used; [24]; Table 1).

As Table 1 illustrates, before the development of wind energy in the state, coal was the biggest source of power in 


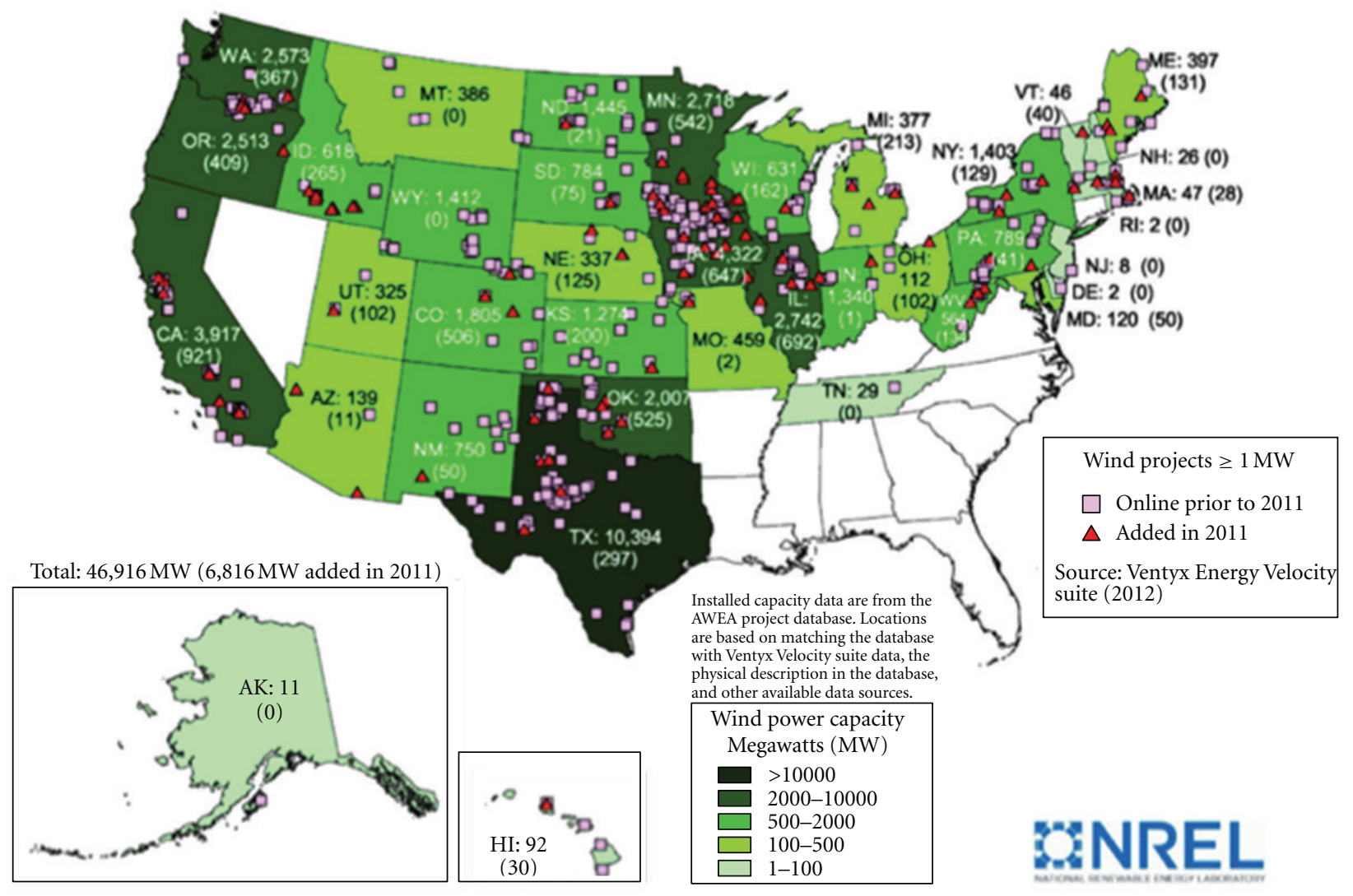

FIGURE 1: Installed capacity (source National Renewable Energy Laboratory).

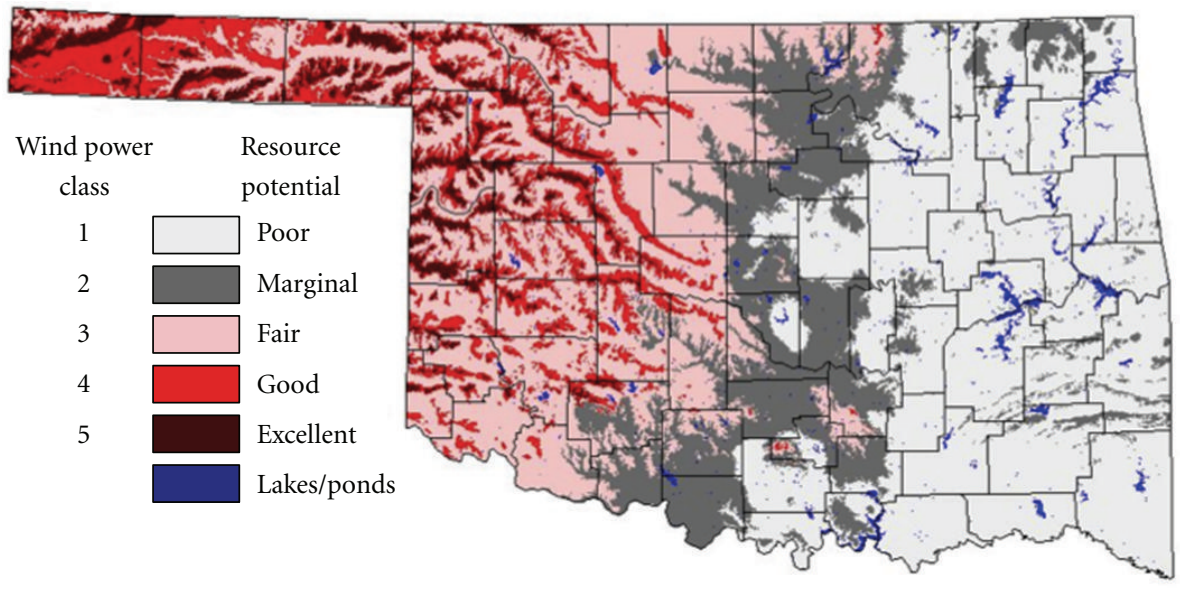

FIGURE 2: Wind resource in Oklahoma see [19].

Oklahoma. In 2002, Oklahoma's electric power industry via coal alone emitted 165,000 tons of Sulfur Dioxide, 76,000 tons of Nitrogen Oxide, and 40,424,000 tons of Carbon Dioxide into the atmosphere. Reduction numbers shown in the results below used wind power as a replacement for coal in Oklahoma, following previous research (e.g., $[14,16,17])$. Thus, a conversion between installed capacity and pollution per megawatt hour of production needs to be accomplished. The conversion is based upon numbers provided by previous efforts [24-26]. Thus, the installed capacity numbers shown in Figure 1 need to be converted to MW hours (MWh) of production. For example, at the end of 2005, there was $474.45 \mathrm{MW}$ of installed wind capacity in Oklahoma. This means that at optimal wind speeds, $474.45 \mathrm{MW}$ of electricity can be produced every hour. Multiply this by 24 hours a day and 365.25 days per year yields approximately $4,160,000 \mathrm{MW}$-hours of electricity per year. This value then can be multiplied by a combination of the fuel mix as shown 


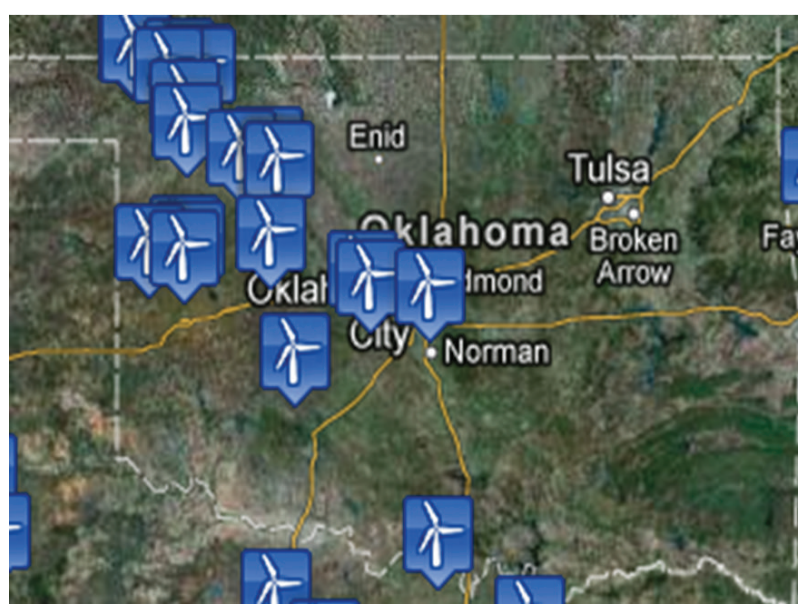

FIGURE 3: Location of wind farms in Oklahoma see [23].

TABle 1: Prewind fuel mix for Oklahoma.

\begin{tabular}{lcc}
\hline Type & Energy source (Trillion Btu) & Percent (\%) \\
\hline Coal & 361.6 & 64 \\
Natural gas & 179.3 & 32 \\
Petroleum & 1.5 & 0 \\
Hydropower & 22.5 & 4 \\
\hline
\end{tabular}

(Data for Table 1 obtained from [24]).

above, and the known emissions of the different fuel types [24-26]. However, the wind does not blow all the time, so an estimate of the percent of total capacity generated by the wind must be estimated. Previous research $[9,10,27]$ has examined the Oklahoma wind resource. Using this analysis of the typical wind speeds in the state their overall distribution, as well as analysis of more recent research by the US DOE [1], a "capacity factor" value of 0.37 was used to produce the estimates of emissions reduction. This provides a comparative value which can be used for both the past and future estimates of the emissions reduction. Thus, for the example above, the 4,160,000 MW hours of electricity for 2005 would be multiplied by 0.37 to produce an estimate of slightly more than $1,540,000$ of actually produced MW hours of electricity. This number for each year needs to then be multiplied by the estimated tons/MWh reduction as provided by an analysis of the previous research (e.g., for $\mathrm{SO}_{2}$, this factor has been estimated to be approximately 0.0046).

Figure 4 shows the results of this analysis. As can be seen, the state of Oklahoma has been spared over 26 million tons of pollution from $\mathrm{SO}_{2}, \mathrm{NO}_{X}$, and $\mathrm{CO}_{2}$ that otherwise would have been emitted over the last decade. The greatest amount (over 90\%) of this comes from Carbon Dioxide. However, there also was a large amount of reduction in the other pollutants as well, and, as will be seen below, the $\mathrm{SO}_{2}$ and $\mathrm{NO}_{X}$ values become more significant in terms of projected morbidity and cost savings. These values also show the greatest increase in pollution savings associated with the large buildup of wind turbines from 2009-2011. These results are similar to the Delarue et al. $[14,15]$ results showing $\mathrm{CO}_{2}$ emission reduction would reach a level of $1.26 \mathrm{kton}$ of $\mathrm{CO}_{2}$

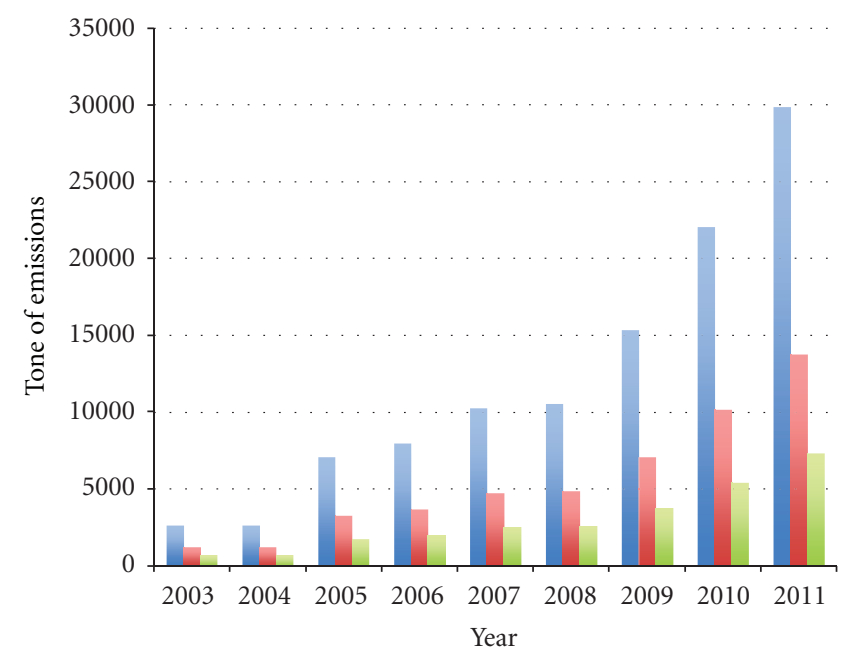

Sulfur Dioxide

Nitrous Oxide

- Carbon Dioxide (thousand tons)

FIGURE 4: Estimated emissions reductions.

avoided per MW of installed wind power capacity per year. Although the numbers are different, they are also reasonably similar to Holttinen and Tuhkanen [17] who found a reduction of from 300-700 $\mathrm{g}$ in Finland if all fuels replaced by wind production a $\mathrm{CO}_{2}$ reduction is achieved. Note that Finland and Belgium have a different fuel blend than Oklahoma, so the values themselves are similar but different.

\section{Health Impact}

Once the pollution reduction estimates were produced, the next step was to develop an estimate of the projected health impacts of a reduction in pollution. For this portion, the analysis focused on $\mathrm{SO}_{2}$ and $\mathrm{NO}_{X}$, as the health benefits of a $\mathrm{CO}_{2}$ reduction solely from Oklahoma wind energy would be negligible. The greatest impact from a $\mathrm{CO}_{2}$ reduction would be a projected reduction in climate change in the future. The health estimates shown in Figures 5 and 6 were calculated using numbers from US EPA and EIA [24-26]. The EPA, as part of it Clear Skies Initiative, provided a sophisticated way to convert emissions to health effects, using population, proximity to utility plants, average age of population, and other variables. Also, as illustrated by Rabl and Spadaro [28], detailed analysis should include specific models associated with the exposure-response or concentration-response. As Rabl and Spadaro [28] show, these can be quite complex. Since the purpose of this study is not to develop a new method of analysis to convert emissions reduction to health impacts, the numbers from the Clear Skies analysis were normalized to the Oklahoma case to produce an estimate of ratio of deaths, heart attacks, and so forth per ton of Sulfur Dioxide and Nitrous Oxides (although it should be noted that the overwhelming majority of the positive health impact will come from a reduction in the $\mathrm{SO}_{2}$ values, as it is $\mathrm{SO}_{2}$ that has been shown to be the most important from a health standpoint in previous research $[4,5]$, and so forth. This ratio was then 


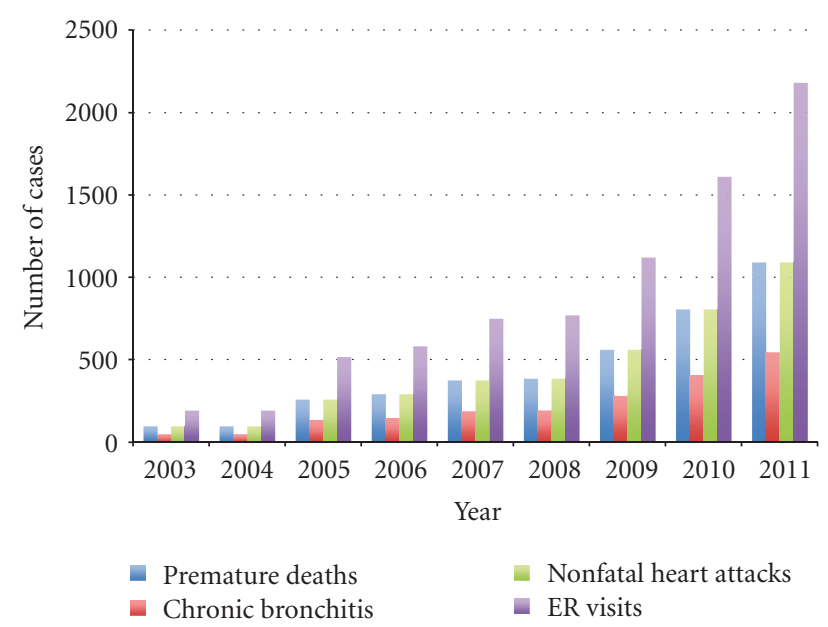

FIgURE 5: Health impacts of emissions reduction.

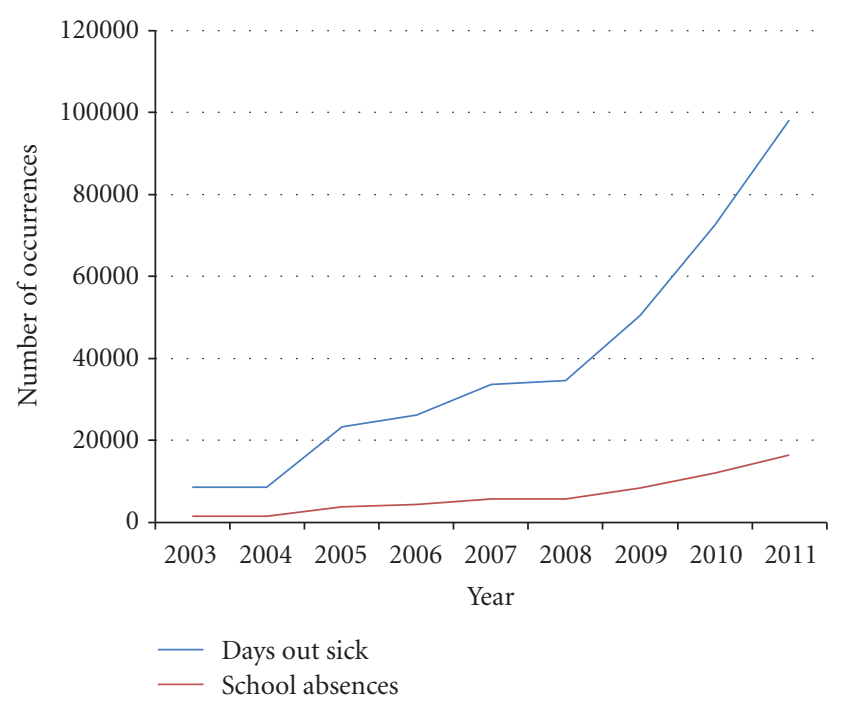

FIgURE 6: Additional impacts of emissions reduction.

multiplied by the pollution emissions eliminated due to wind power to produce the results shown in Figures 5 and 6.

Figure 5 shows the reduction in various types of health impacts associated with the reduced atmospheric pollutants. Current estimates for 2011 are for a reduction of over 1000 premature deaths in Oklahoma. Based on previous research, these deaths are most likely to be associated with respiratory ailments related to inhaling harmful pollutants for an extended period of time. Also for 2011, the estimated health benefits include a reduction of over 2000 hospital visits, 500 cases of chronic bronchitis, and 1000 nonfatal heart attacks. These values have more than tripled over the last four years, and clearly illustrate the health benefits brought on by the increased use of wind energy in Oklahoma. Figure 6 shows the same pattern for two different, yet also interesting variables, days out sick from work and school absences. Again, there is a notable increase over the last few years, with the values for the out sick variable, for example, changing from just over 25,000 in 2006 to over 90,000 in 2011.

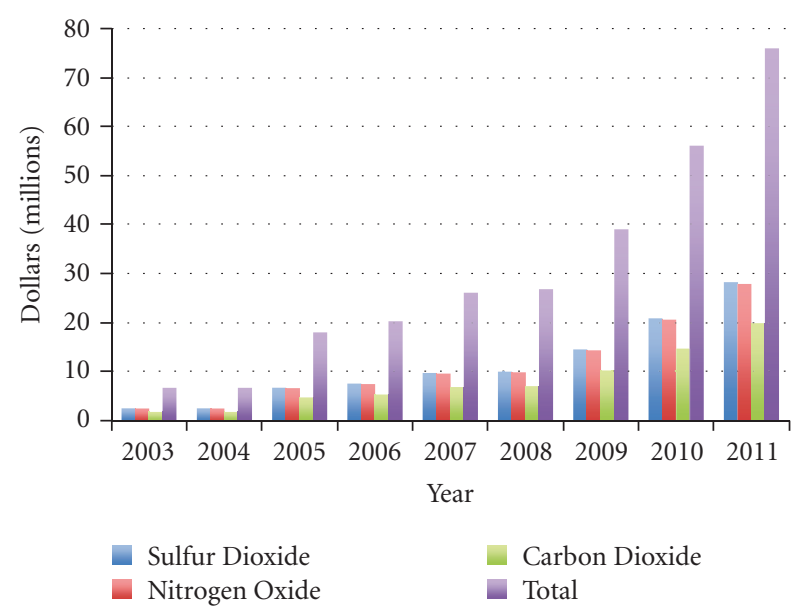

FIgURE 7: Potential market value of pollution emissions.

\section{Economic Analysis}

Finally, an attempt was made to examine the potential economic impact of the pollution reduction. This was accomplished in two different ways. The first way was to examine the potential market value of the pollutants. With increasing government regulations on air quality and international and national law and proposals such as the Kyoto Protocol and the Clear Skies Act [26], pollutants displaced via wind energy could be sold as "allowances" in the future. The rationale here is that part of a government (or multigovernment) program to allow a free-market incentive to reduce emissions, pollutants such as $\mathrm{CO}_{2}, \mathrm{SO}_{2}$, and $\mathrm{NO}_{X}$ can be bought and sold on the open market in a program known as "Cap and Trade", whereby the regulating authority sets a maximum (or "cap") for the pollutant and then allows the pollutant to be traded. This type of program is currently in place as part of the Clean Air Act in the US and the Kyoto Protocol in Europe. Spot prices for these commodities can also be found on the respective commodities trading boards and were used to estimate the potential market value of the pollutants should they be allowed to be traded in the US. Thus, each ton of pollutant has a value associated with it $[29,30]$. For example, although the spot price for Carbon Dioxide has varied dramatically, it can be estimated at approximately $\$ 2 /$ ton [31,32]. Figure 7 shows a combined analysis of these two estimates of the economic impacts. The values show an approximately $\$ 76$ million benefit to the state through potential emission-trading credits. This is split almost evenly between the three pollutants, with $\mathrm{SO}_{2}$ accounting for $\$ 28.5$ million, $\mathrm{NO}_{X} \$ 27.9$ million, and $\mathrm{CO}_{2}$ close to $\$ 20$ million for 2011. Again, the reader is reminded that for $\mathrm{NO}_{X}$ and $\mathrm{CO}_{2}$ no such program is currently in place, but rather these numbers are used as a guide for the potential benefits.

A second estimate of the economic benefit associated with the reduced health problems described above was also undertaken. This was accomplished using the numbers estimated by Rabl and Spadaro [28]. Rabl and Spadaro produced the following for the health savings associated with the reduced pollutant emissions from renewable energy. As 
mentioned above, $\mathrm{SO}_{2}$ is considered the major pollutant for respiratory and other pollution-related ailments. Rabl found the conversion number for the economic impact of Sulphur Dioxide to be 0.3 Euros/KG. Thus, for Oklahoma, this represents a savings of $\$ 13$ million in 2011 and over $\$ 42$ million since 2003.

\section{Conclusion and Summary}

Oklahoma's renewable resource assets place it among the leading states for potentially attracting future development in renewable energy and associated technologies that add value to the resource base. One way to measure the impact of wind energy is to measure the economic impact. In 2010, the economic impact in Oklahoma was measured as supporting close to 2000 jobs, annual property tax payments of over $\$ 9$ million, and annual land lease payments of over $\$ 4$ million [20]. Another, less common way to examine the impact is to attempt to measure the environmental, health, and economic impact associated with the reduction of pollution emissions as there is a switch from coal and natural gas to wind as the means to produce electricity in the state. This paper represents the first attempt to quantify these numbers specifically for Oklahoma. Results show a savings of millions of tons of $\mathrm{CO}_{2}, \mathrm{SO}_{2}$, and $\mathrm{NO}_{X}$, with an associated health savings of over 1000 lives, and thousands of reduced cases of nonfatal heart attacks, chronic bronchitis, and hospital admissions. Using numbers estimated by previous methodological studies, these values represent a savings of tens of millions of dollars annually. There is also a potential economic benefit to using the pollution reduction in a "Cap and Trade" program. Results show, again, a net benefit of tens of millions of dollars.

Finally, as mentioned above, DOE looked at ways to ensure that wind energy would meet $20 \%$ of the United States energy demand by 2030 [2]. In that report, they list Oklahoma as having an estimated $18 \mathrm{GW}$ of installed wind energy capacity by 2030, which is almost ten times the value reported for 2011, so one can take any of the numbers presented in the analysis here and increase it by an order of magnitude to obtain the projected future benefits of tens of thousands of lives and hundreds of millions of dollars annually. Thus, as we look to the future, the benefits of renewable energy are clear and provide a path to achieve economic growth along with improved environmental stewardship.

\section{Acknowledgments}

The authors would like to recognize the Oklahoma Economic Development Generating Excellence program, the US Department of Energy, and the Oklahoma State Energy Office for providing funding for this work. They would also like to thank Mr. Brian Paris for his help with data collection and analysis.

\section{References}

[1] R. Wiser and M. Bolinger, Wind Technologies Market Report, Wind \& Water Power Program, Office of Energy Efficiency and Renewable Energy of the U.S. Department of Energy, 2012.
[2] Department of Energy, 20 Percent Wind By 2030, Washington, DC, USA, 2008.

[3] National Science Foundation, Executive Summary Environmental Impacts of Wind-Energy Projects, Washington, DC, USA, 2007.

[4] G. D. Leikauf, S. Kline, R. E. Albert et al., "Evaluation of a possible association of urban air toxics and asthma," Environmental Health Perspectives, vol. 103, no. 6, pp. 253-271, 1995.

[5] J. Corburn, "Urban land use, air toxics and public health: assessing hazardous exposures at the neighborhood scale," Environmental Impact Assessment Review, vol. 27, no. 2, pp. 145-160, 2007.

[6] K. E. Smoyer, L. S. Kalkstein, J. S. Greene, and H. Ye, “The impacts of weather and pollution on human mortality in Birmingham, Alabama and Philadelphia, Pennsylvania," International Journal of Climatology, vol. 20, no. 8, pp. 881-897, 2001.

[7] J. S. Greene, L. S. Kalkstein, D. Mills, and J. Samenow, "An examination of climate change on extreme heat events and climate/mortality relationships in large US cities," Journal of Weather, Climate, and Society, vol. 3, pp. 281-292, 2011.

[8] X. Lu, M. B. McElroy, and N. A. Sluzas, "Costs for integrating wind into the future ERCOT system with related costs for savings in $\mathrm{CO}_{2}$ emissions," Environmental Science and Technology, vol. 45, no. 7, pp. 3160-3166, 2011.

[9] M. L. Morrissey, W. E. Cook, and J. S. Greene, "An improved method for estimating the wind power density distribution function," Journal of Atmospheric and Oceanic Technology, vol. 27, no. 7, pp. 1153-1164, 2010.

[10] M. L. Morrissey, A. Albers, J. S. Greene, and S. Postawko, "An isofactorial change-of-scale model for the wind speed probability density function," Journal of Atmospheric and Oceanic Technology, vol. 27, no. 2, pp. 257-273, 2010.

[11] E. Denny and M. O'Malley, "Wind generation, power system operation, and emissions reduction," IEEE Transactions on Power Systems, vol. 21, no. 1, pp. 341-347, 2006.

[12] N. Blair, M. Hand, W. Short, and P. Sullivan, "Modeling sensitivities to the $20 \%$ wind scenario report with the WinDS model," in Proceedings of the American Wind Energy Association WindPower Conference, Houston, Tex, USA, June 2008.

[13] Department of Energy, "Reduced form of detailed modeling of wind transmission and intermittency for use in other models," Tech. Rep. NREL/PO-620-38453, 2005.

[14] E. Delarue, P. Luickx, and W. D'haeseleer, The Effect of Implementing Wind Power on Overall Electricity Costs, $\mathrm{CO}_{2}$ Emissions and Reliability, Katholieke Universiteit Leuven, 2008.

[15] E. D. Delarue, P. J. Luickx, and W. D. D’haeseleer, “The actual effect of wind power on overall electricity generation costs and $\mathrm{CO}_{2}$ emissions," Energy Conversion and Management, vol. 50, no. 6, pp. 1450-1456, 2009.

[16] H. A. Gil and G. Joos, "Generalized estimation of average displaced emissions by wind generation," IEEE Transactions on Power Systems, vol. 22, no. 3, pp. 1035-1043, 2007.

[17] H. Holttinen and S. Tuhkanen, "The effect of wind power on $\mathrm{CO}_{2}$ abatement in the Nordic Countries," Energy Policy, vol. 32, no. 14, pp. 1639-1652, 2004.

[18] W. Katzenstein and J. Apt, "Air emissions due to wind and solar power," Environmental Science and Technology, vol. 43, no. 2, pp. 253-258, 2009.

[19] Oklahoma Wind Power Initiative, 2012, http://www.ocgi .okstate.edu/owpi. 
[20] American Wind Energy Association, Wind Energy Facts-Oklahoma, 2011.

[21] Department of Energy Wind Powering America, http://www .windpoweringamerica.gov/wind_installed_capacity.asprat.

[22] Oklahoma Wind Power Initiative, 2012, http://www2.ocgi .okstate.edu/website/owpi2/viewer.htm.

[23] Open Energy, Map of Wind Farms, 2012, http://en.openei .org/wiki/Map_of_Wind_Farms.

[24] Energy Information Agency, 2012, http://www.eia.gov/electricity/state/.

[25] Environmental Protection Agency, 2012, http://www.epa.gov/ air/.

[26] Environmental Protection Agency, 2012, http://www.epa.gov/ clearskies/.

[27] S. Greene, K. McNabb, R. Zwilling, M. Morrissey, and S. Stadler, "Analysis of vertical wind shear in the Southern Great Plains and potential impacts on estimation of wind energy production," International Journal of Global Energy Issues, vol. 32, no. 3, pp. 191-211, 2009.

[28] A. Rabl and J. V. Spadaro, "Public health impact of air pollution and implications for the energy system," Annual Review of Energy and the Environment, vol. 25, pp. 601-627, 2000.

[29] L. Johnston, E. Hausman, A. Sommer et al., Climate Change and Power: Carbon Dioxide Emissions Costs and Electricity Resource Planning, Synapse Energy Economics, Cambridge, Mass, USA, 2006.

[30] J. Bluestein, E. Salerno, L. Bird, and L. Vimmerstedt, "Incorporating Wind Generation in Cap and Trade Programs," Tech. Rep. NREL/TP-500-40006, 2006.

[31] Chicago Climate Exchange, 2012, https://www.theice .com/ccx.jhtml.

[32] Carbon Trade Exchange, 2012, http://carbontradexchange .com/. 


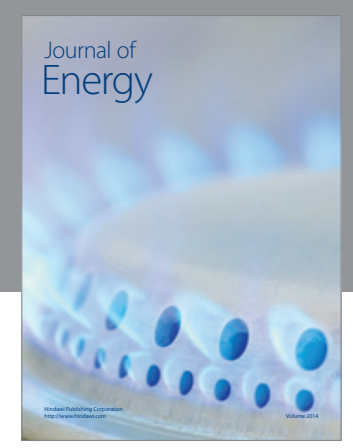

Journal of

Industrial Engineering
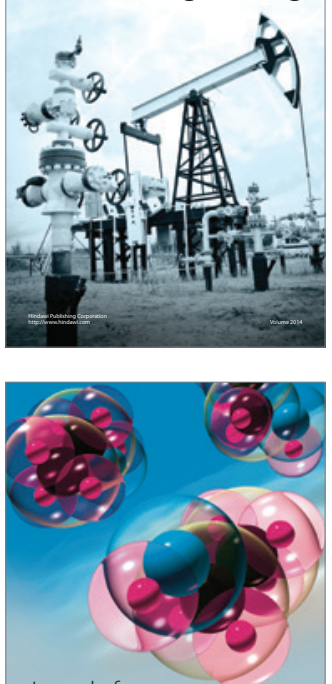

Fuels
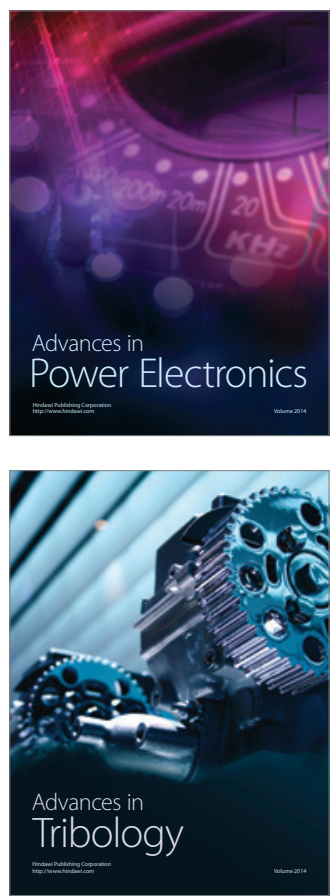

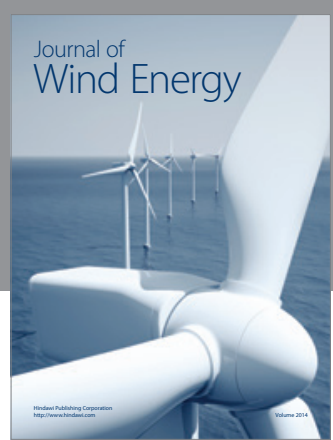

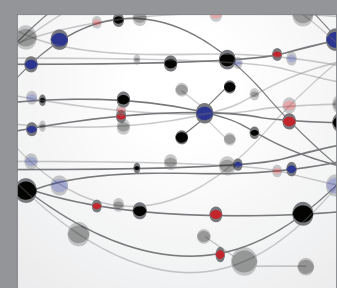

The Scientific World Journal

Submit your manuscripts at http://www.hindawi.com

Journal of

Structures
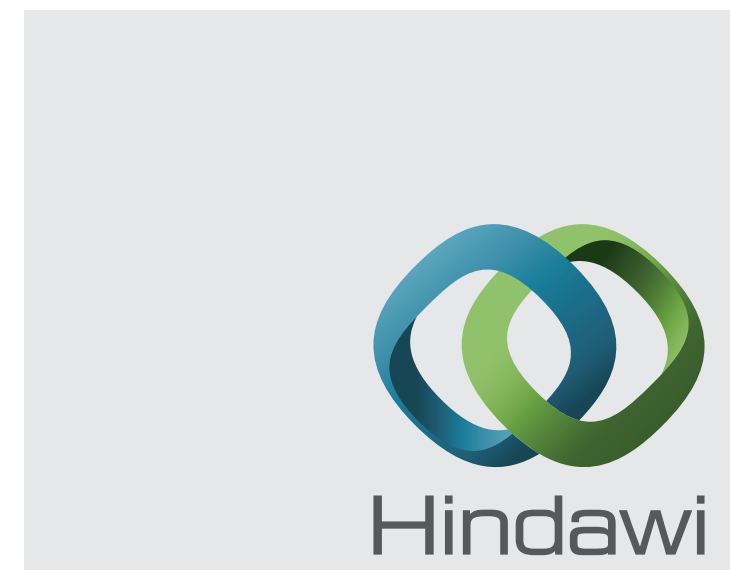

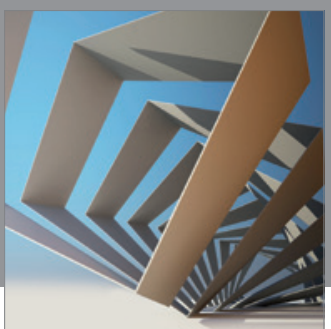

Rotating

Machinery
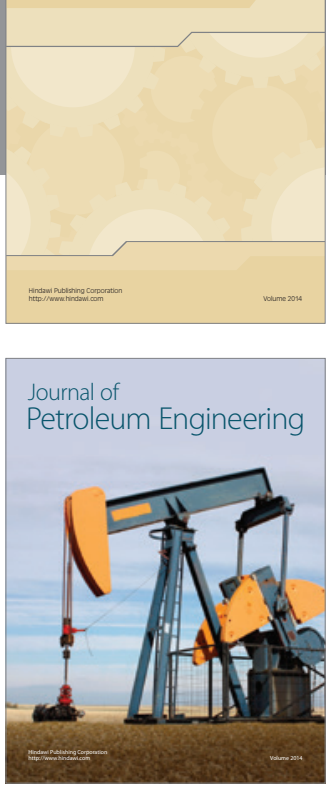

Journal of

Solar Energy
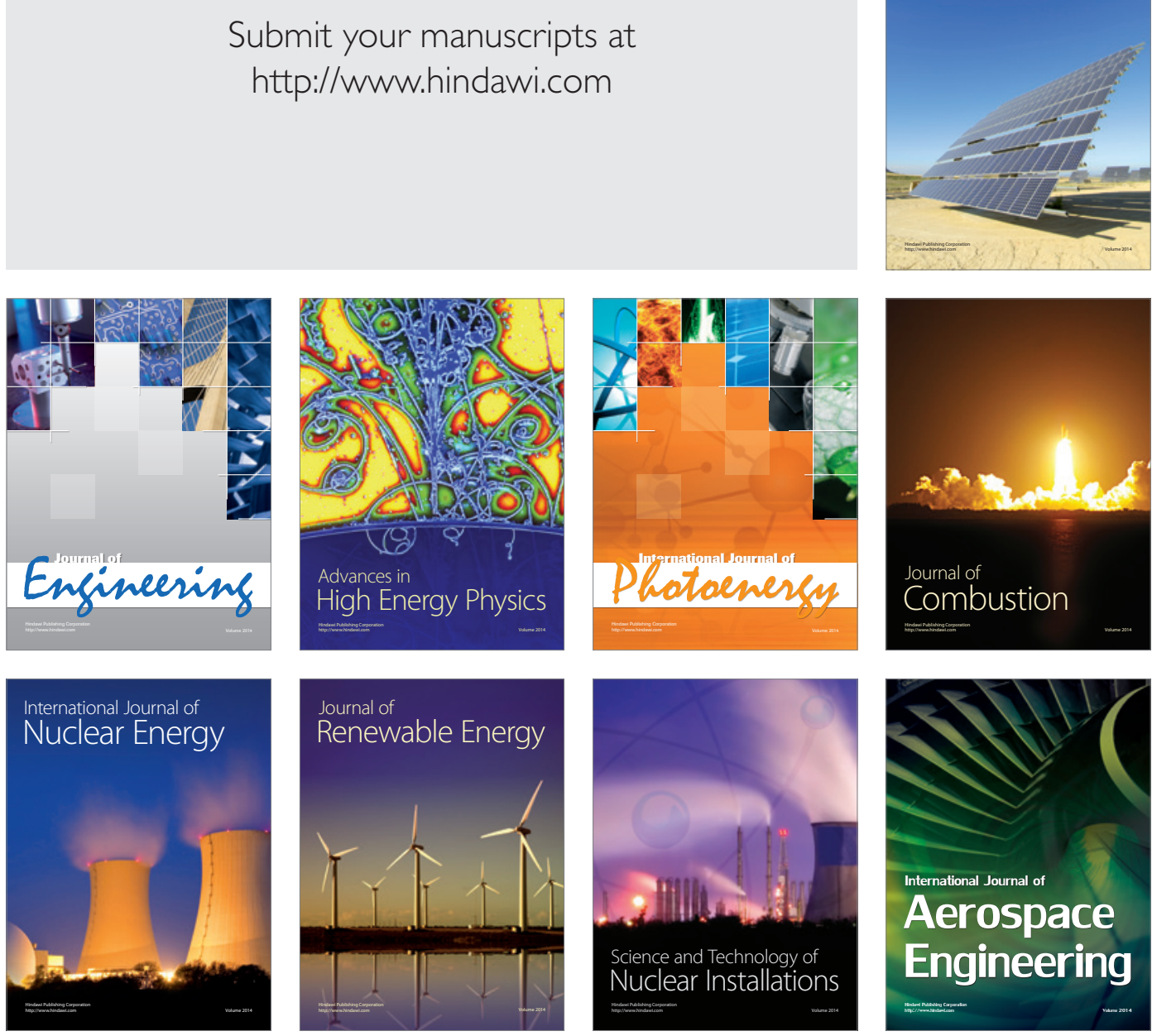